Article

\title{
Finite Element Study on Calculation of Nonlinear Soil Consolidation Using Compression and Recompression Indexes
}

\author{
Chao $\mathrm{Xu}^{1, *}$ and Suli Pan ${ }^{1,2, *}$ \\ 1 College of Civil Engineering and Architecture, Zhejiang University, Hangzhou 310000, China \\ 2 College of Water Resources and Environmental Engineering, Zhejiang University of Water Resources and \\ Electric Power, Hangzhou 310000, China \\ * Correspondence: xuchao571@163.com (C.X.); pansuli@zju.edu.cn (S.P.)
}

Received: 24 May 2020; Accepted: 6 July 2020; Published: 9 July 2020

\begin{abstract}
The coefficient of consolidation is traditionally considered as a constant value in soil consolidation calculations. This paper uses compression and recompression indexes to calculate the solution-dependent nonlinear compressibility, thus overconsolidation and normal consolidation are separated during the calculations. Moreover, the complex nonlinear consolidation can be described using the nonlinear compressibility and a nonlinear permeability. Then, the finite element discrete equation with consideration of the time-dependent load is derived, and a corresponding program is developed. Subsequently, a case history is conducted for verifying the proposed method and the program. The results show that the method is sufficiently accurate, indicating the necessity of considering nonlinearity for consolidation calculations. Finally, three cases are compared to reveal the importance of separating the overconsolidation and normal consolidation. Overall, this study concluded that it is inadequate to consider just one consolidation status in calculations, and that the proposed method is more reasonable for guiding construction.
\end{abstract}

Keywords: compression index; recompression index; nonlinear consolidation; finite element method; time-dependent loading

\section{Introduction}

Consolidation behavior is a complex phenomenon in clays and is of great importance to most construction activities. The accuracy of consolidation calculations is a key point in the geotechnical field. Terzaghi developed the classical consolidation theory for solving consolidation problems [1]. However, this theory is based on many assumptions, such as constant loading and a constant coefficient of consolidation. In particular, the constant consolidation coefficient will lead to incorrect results in the multilayered soil system [2]. To improve the calculation accuracy, many modifications of the assumptions have been proposed. Past studies mainly investigated the variations of material parameters, such as the permeability and the compressibility [3-10], and many advances related to varying loading, which better reflect real constructions, were obtained [11-15]. As a simplification of inhomogeneity along depth, multilayered soil was studied [16-20]. Other important calculation factors, such as drainage boundary conditions [21-24] and the non-Darcy fluid theory [25-28], were also considered for more reasonable calculations. Although some of these early studies obtained analytical solutions, a majority of them have not been analytically solved. With the development of numerical methods, complex consolidation equations can be solved efficiently, thereby allowing many modifications to be incorporated into the consolidation calculations. The finite element method $[2,7,29,30]$ and the finite difference method $[4,27,31-33]$ are the two most commonly used methods. Moreover, other effective numerical methods were also adopted [34-37]. 
However, the coefficient of consolidation used in calculation is usually considered as a constant value in aforementioned studies (i.e., a constant ratio of permeability to compressibility), and such a simplification may not be reasonable in some situations. In particular, there is little information available about the solution-dependent behavior of the compressibility, which significantly affects the coefficient of consolidation. Compression and recompression indexes, which are used in calculations of settlement, are used herein for evaluating the nonlinear compressibility. Subsequently, the nonlinear compressibility and a nonlinear permeability are combined to describe the nonlinear consolidation. Using the finite element method, the discrete equation in space and time domains is derived and the corresponding program with consideration of the time-dependent load is developed. A case history for verifying the proposed method and three comparative cases for proving the significance of the separation of overconsolidation and normal consolidation are conducted subsequently.

\section{Nonlinear Consolidation}

\subsection{Nonlinear Compressibility}

On the basis of consolidation theory, the relation of void ratio and effective stress in soil is described as [38]

$$
\partial e=-a_{v} \partial \sigma^{\prime}
$$

where $e$ is the void ratio, $\sigma^{\prime}$ is the effective stress, and $a_{v}$ is the compressibility.

According to the relation of $e-\log \sigma^{\prime}$ [38] shown in Figure 1, the increment of void ratio can be calculated using Equation (2) for overconsolidation and Equation (3) for normal consolidation:

$$
\begin{aligned}
& d e=-C_{s} d\left(\log \sigma^{\prime}\right)=-\frac{C_{s}}{2.303} \frac{d \sigma^{\prime}}{\sigma^{\prime}} \\
& d e=-C_{c} d\left(\log \sigma^{\prime}\right)=-\frac{C_{c}}{2.303} \frac{d \sigma^{\prime}}{\sigma^{\prime}}
\end{aligned}
$$

where $d e$ is the increment of void ratio, $C_{s}$ is the recompression index, $C_{c}$ is the compression index, and $d \sigma^{\prime}$ is the increment of effective stress.

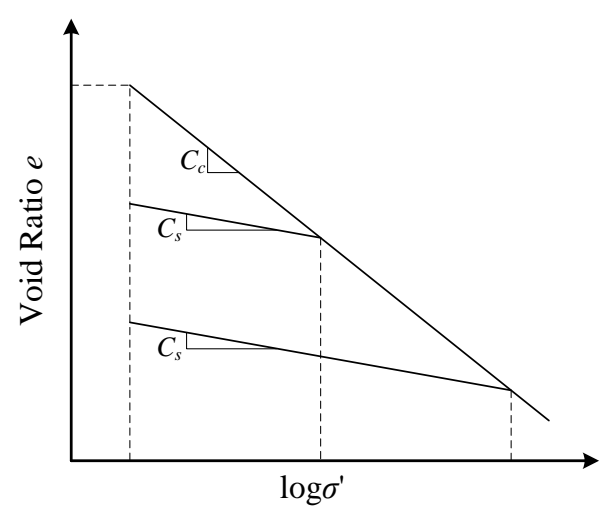

Figure 1. The diagram of $e-\log \sigma^{\prime}$ relation.

From Equations (1)-(3), the nonlinear compressibility, which can be calculated using the compression index or the recompression index, is obtained and expressed as

$$
a_{v}= \begin{cases}\frac{C_{S}}{2.303 \sigma^{\prime}} & \text { Overconsolidation } \\ \frac{C_{c}}{2.303 \sigma^{\prime}} & \text { Normal Consolidation }\end{cases}
$$




\subsection{Nonlinear Permeability}

For the nonlinear permeability, the kind of $e-\log k$ relation [31], which is mathematically described in Equation (5), is adopted:

$$
\log k=\log k_{0}-\frac{e_{0}-e}{C_{k}}
$$

where $k_{0}$ is the initial permeability, $e_{0}$ is the initial void ratio, $k$ is the current permeability corresponding to current void ratio $e$, and $C_{k}$ is the permeability index.

\subsection{Degree of Consolidation}

The average degree of consolidation used in this paper is defined as [38]

$$
u_{a v}=\frac{q_{t}-(1 / H) \int_{0}^{H} u d z}{q_{c}}
$$

where $u_{a v}$ is the average degree of consolidation, $u$ is the excess pore water pressure, $q_{t}$ is the current load at time $t, q_{c}$ is the ultimate load when $t$ approaches to $\infty$, and $H$ is the calculation depth.

For multilayered soil, Equation (7) should be used:

$$
u_{a v}=\frac{q_{t}-(1 / H) \sum_{i=1}^{n} \int_{z_{i-1}}^{z_{i}} u_{i} d z}{q_{c}}
$$

where $n$ is the number of layers, or the number of elements in the finite element analyses.

\subsection{Settlement}

Settlement of any depth at any time can be evaluated using Equation (8):

$$
S(t, z)=\sum_{i=1}^{t}\left[\int_{0}^{z} \frac{-\Delta e_{i}}{1+e_{0}} d z\right]
$$

\section{Finite Element Solution}

\subsection{Finite Element Equations}

The governing equation of small strain problems in the consolidation theory [38] is written as

$$
\frac{\partial}{\partial z}\left(\frac{k}{\gamma_{w}} \frac{\partial u}{\partial z}\right)=\frac{a_{v}}{1+e_{0}}\left(\frac{\partial u}{\partial t}-\frac{\partial \sigma}{\partial t}\right)
$$

where $\sigma$ is the total stress, $\gamma_{w}$ is the unit weight of water, $t$ is the time, and $z$ is the depth.

Using the Galerkin weighted residual method [30], Equation (9) can be converted to Equation (10):

$$
\left[\mathbf{k}_{c}\right]\{\mathbf{u}\}+\left[\mathbf{m}_{m}\right]\left\{\frac{\partial \mathbf{u}}{\partial t}\right\}=\{\mathbf{f}\}
$$

where $\left[\mathbf{k}_{c}\right]$ is the fluid conductivity matrix, $\left[\mathbf{m}_{m}\right]$ is the mass matrix, $\{\mathbf{u}\}$ is the excess pore water pressure vector, $\{\partial \mathbf{u} / \partial t\}$ is the derivative of excess pore water pressure vector with respect to time, and $\{\mathbf{f}\}$ is the external total load vector. For a one-dimensional line element with two nodes, expressions of the matrices and the vector are Equations (11)-(13).

$$
\left[\mathbf{k}_{c}\right]=\frac{k}{\gamma_{w} L}\left[\begin{array}{cc}
1 & -1 \\
-1 & 1
\end{array}\right]
$$




$$
\begin{gathered}
{\left[\mathbf{m}_{m}\right]=\frac{a_{v} L}{1+e_{0}}\left[\begin{array}{ll}
1 / 3 & 1 / 6 \\
1 / 6 & 1 / 3
\end{array}\right]} \\
\{\mathbf{f}\}=\frac{a_{v} L}{2\left(1+e_{0}\right)} \frac{\partial \sigma}{\partial t}\left\{\begin{array}{l}
1 \\
1
\end{array}\right\}
\end{gathered}
$$

where $L$ is the length of the line element. Then, a kind of interpolation in the time domain using the $\theta$ method [2] made here is as follows:

$$
\{\mathbf{u}\}_{1}=\{\mathbf{u}\}_{0}+\Delta t\left[(1-\theta)\left\{\frac{\partial \mathbf{u}}{\partial t}\right\}_{0}+\theta\left\{\frac{\partial \mathbf{u}}{\partial t}\right\}_{1}\right]
$$

where 0 is the subscript indicating the beginning of a time increment, 1 is the subscript indicating the end of a time increment, $\Delta t$ is the value of the time increment, and $\theta$ is the weighted coefficient $(0 \leq \theta \leq 1)$.

Combining Equations (10) and (14) with the method introduced by Huang and Griffiths [2], the finite element discrete equation, both in space and time domains, is derived as

$$
\left\{\left[\mathbf{m}_{m}\right]+\theta \Delta t\left[\mathbf{k}_{c}\right]\right\}\{\mathbf{u}\}_{1}=\left\{\left[\mathbf{m}_{m}\right]-(1-\theta) \Delta t\left[\mathbf{k}_{c}\right]\right\}\{\mathbf{u}\}_{0}+\Delta t\left[( 1 - \theta ) \left\{\mathbf{f}_{0}+\theta\left\{\mathbf{f}_{1}\right]\right.\right.
$$

\subsection{Calculation Flow}

On the basis of the equations stated above, the transient nonlinear consolidation problems can be solved using the finite element method, and a corresponding program was developed with FORTRAN. Using this program, the excess pore water pressure, the average degree of consolidation, and the settlement can be obtained simultaneously. The detailed calculation flow is illustrated in Figure 2.

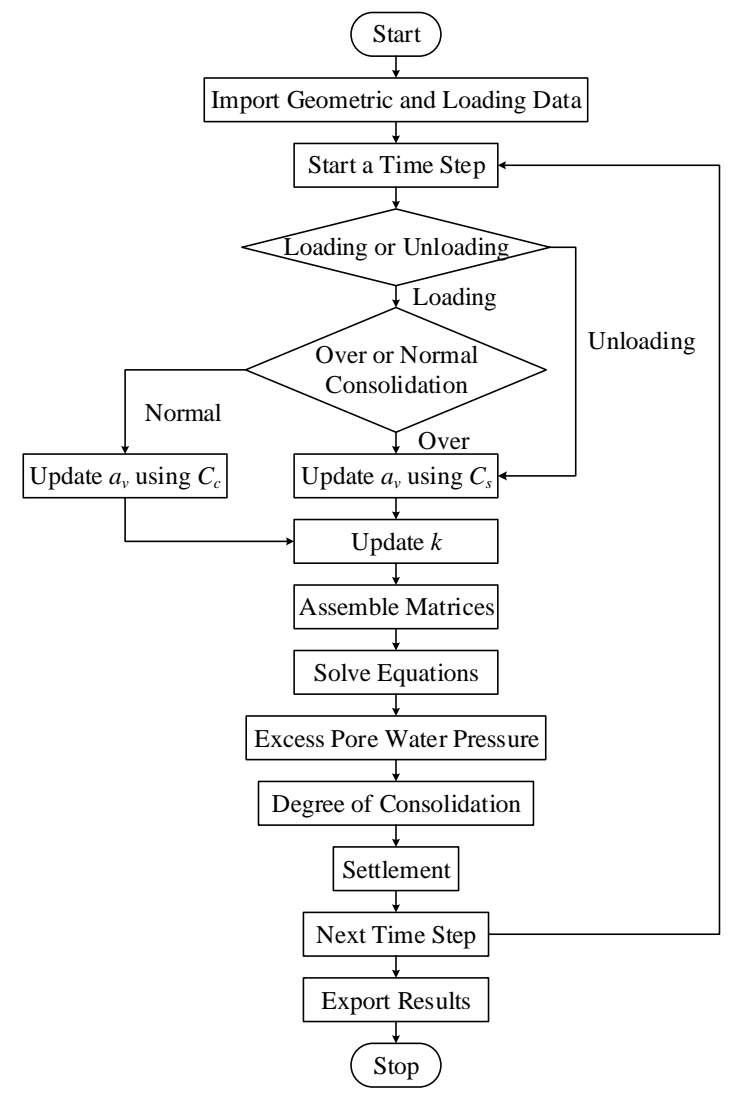

Figure 2. The calculation flow chart based on the finite element method. 


\section{Case Verification}

Case history II from Mesri and Choi [31] is used to verify the proposed method. It was an embankment project, and the construction of this project was finished after 25 days. The final load at the top surface of the foundation is $40.6 \mathrm{kPa}$, the loading process can be dealt with as a linear load (Figure 3). The calculation height of the soil is $14 \mathrm{~m}$ and it is divided into 12 layers; the parameters of all layers are listed in Table 1 . Both top and bottom surfaces are permeable. The calculation time length is 12,000 days, and the unit weight of water is $10 \mathrm{kN} / \mathrm{m}^{3}$.

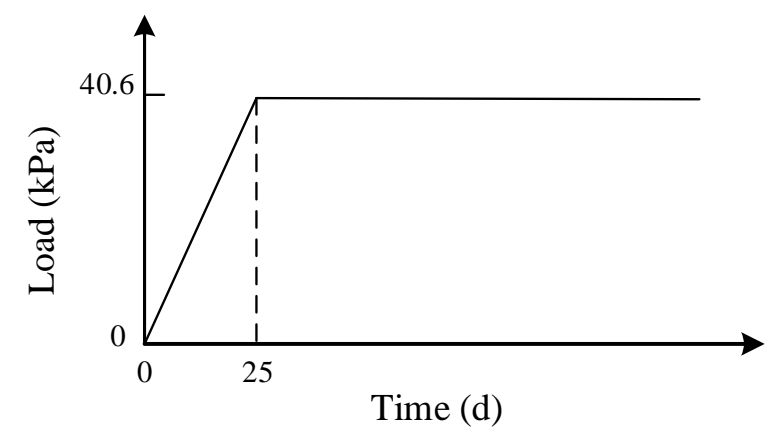

Figure 3. The diagram of the loading process.

Table 1. Recompiled soil parameters after Mesri and Choi [31].

\begin{tabular}{ccccccccc}
\hline Layer & $\boldsymbol{h}(\mathbf{m})$ & $\boldsymbol{k}_{\mathbf{0}}(\mathbf{m} / \mathbf{d})$ & $C_{\boldsymbol{k}}$ & $\boldsymbol{e}_{\mathbf{0}}$ & $\boldsymbol{\sigma}_{\mathbf{0}^{\prime}}(\mathbf{k P a})$ & $\left.\boldsymbol{\sigma}_{p^{\prime}} \mathbf{( k P a}\right)$ & $\boldsymbol{C}_{\boldsymbol{s}}$ & $\boldsymbol{C}_{\boldsymbol{c}}$ \\
\hline 1 & 1 & $8.67 \times 10^{-5}$ & 1.16 & 2.51 & 7.03 & 31.72 & 0.15 & 1.43 \\
2 & 1 & $1.73 \times 10^{-4}$ & 1.34 & 2.91 & 12.11 & 21.98 & 0.19 & 1.89 \\
3 & 0.5 & $1.73 \times 10^{-4}$ & 1.44 & 3.21 & 16.52 & 24.22 & 0.22 & 2.39 \\
4 & 1 & $9.57 \times 10^{-5}$ & 1.34 & 2.99 & 20.14 & 25.43 & 0.14 & 2.40 \\
5 & 1.5 & $1.12 \times 10^{-4}$ & 1.18 & 2.61 & 26.11 & 32.44 & 0.24 & 2.48 \\
6 & 2 & $1.12 \times 10^{-4}$ & 1.18 & 2.61 & 33.39 & 38.14 & 0.27 & 2.63 \\
7 & 0.5 & $9.59 \times 10^{-5}$ & 1.08 & 2.41 & 39.15 & 44.71 & 0.17 & 2.10 \\
8 & 1.5 & $9.64 \times 10^{-5}$ & 0.93 & 2.08 & 46.20 & 54.67 & 0.11 & 2.14 \\
9 & 2 & $9.59 \times 10^{-5}$ & 0.95 & 2.14 & 55.20 & 59.86 & 0.20 & 1.83 \\
10 & 0.5 & $8.61 \times 10^{-5}$ & 1.10 & 2.41 & 59.06 & 72.67 & 0.19 & 2.70 \\
11 & 1.5 & $1.29 \times 10^{-4}$ & 0.70 & 1.56 & 66.44 & 86.94 & 0.12 & 2.81 \\
12 & 1 & $1.30 \times 10^{-4}$ & 0.61 & 1.21 & 74.45 & 89.84 & 0.10 & 2.75 \\
\hline
\end{tabular}

Figures 4 and 5 show comparisons between calculated and measured excess pore water pressure, along time and depth, respectively. While Figures 6 and 7 compare calculated and measured settlement along time and depth, respectively. It is clear from these figures that the calculated results are in good agreement with the measurements, proving the accuracy of the method proposed in this study. Meanwhile, the comparison underscores the necessity of considering the nonlinear permeability and the nonlinear compressibility in calculations, and demonstrates that using compression and recompression indexes for evaluating the nonlinear compressibility is effective and stable. 


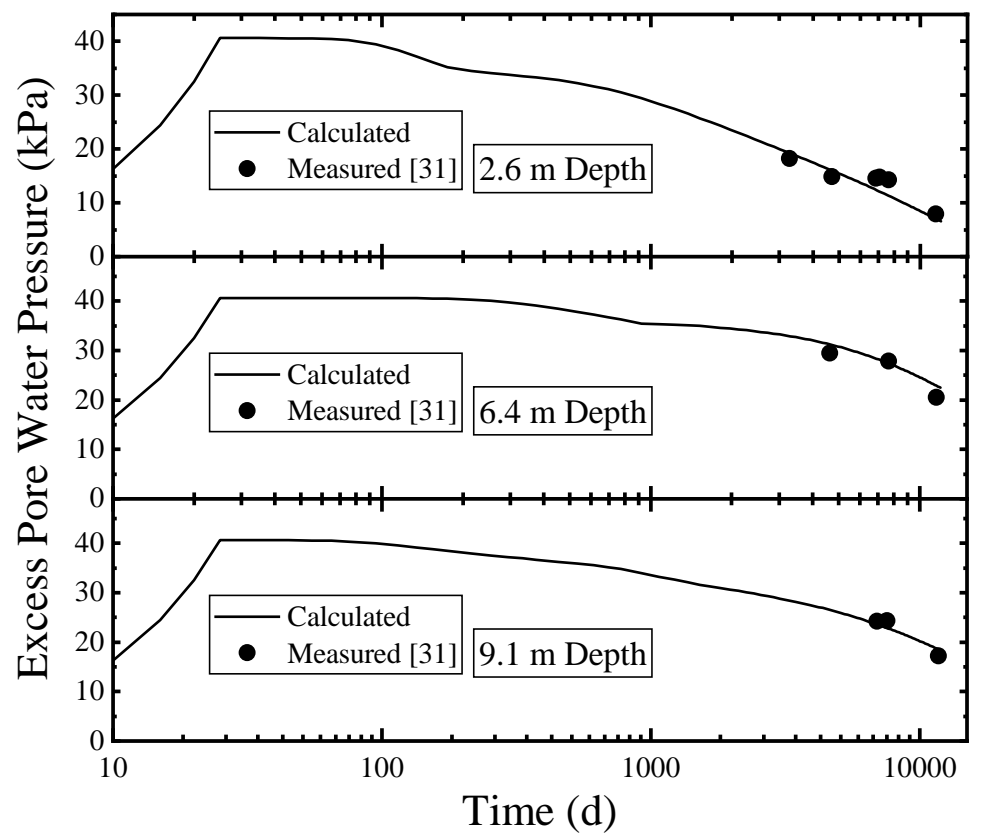

Figure 4. Comparisons of calculated and measured excess pore water pressure along time.

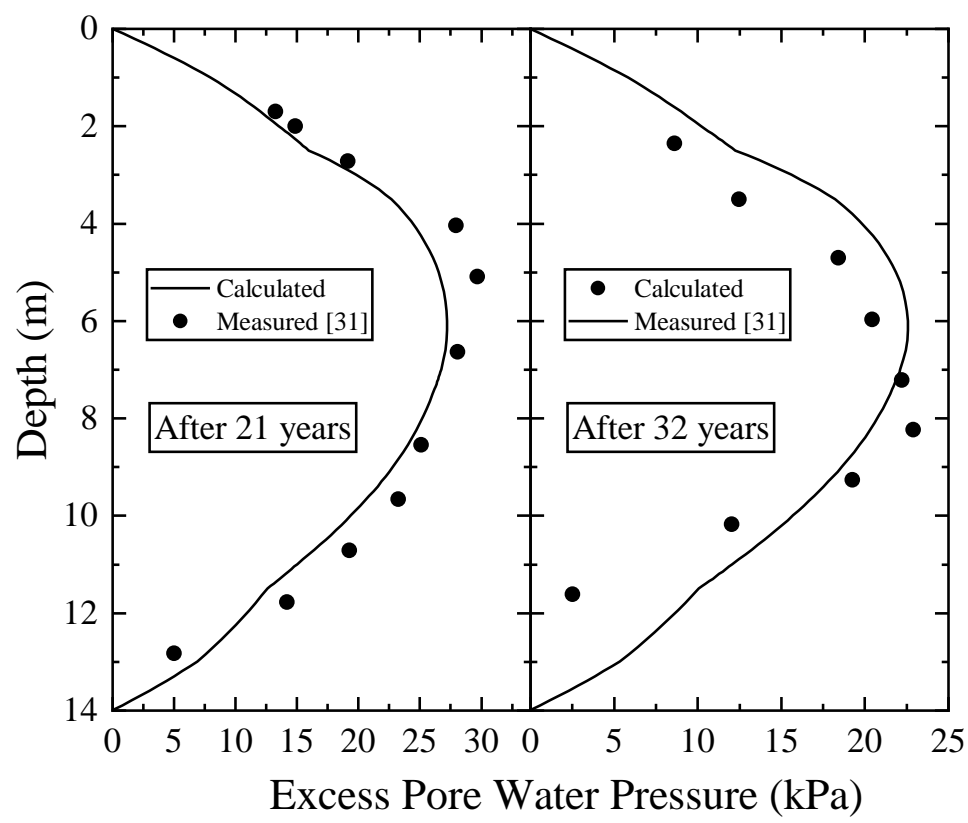

Figure 5. Comparisons of calculated and measured excess pore water pressure along depth. 


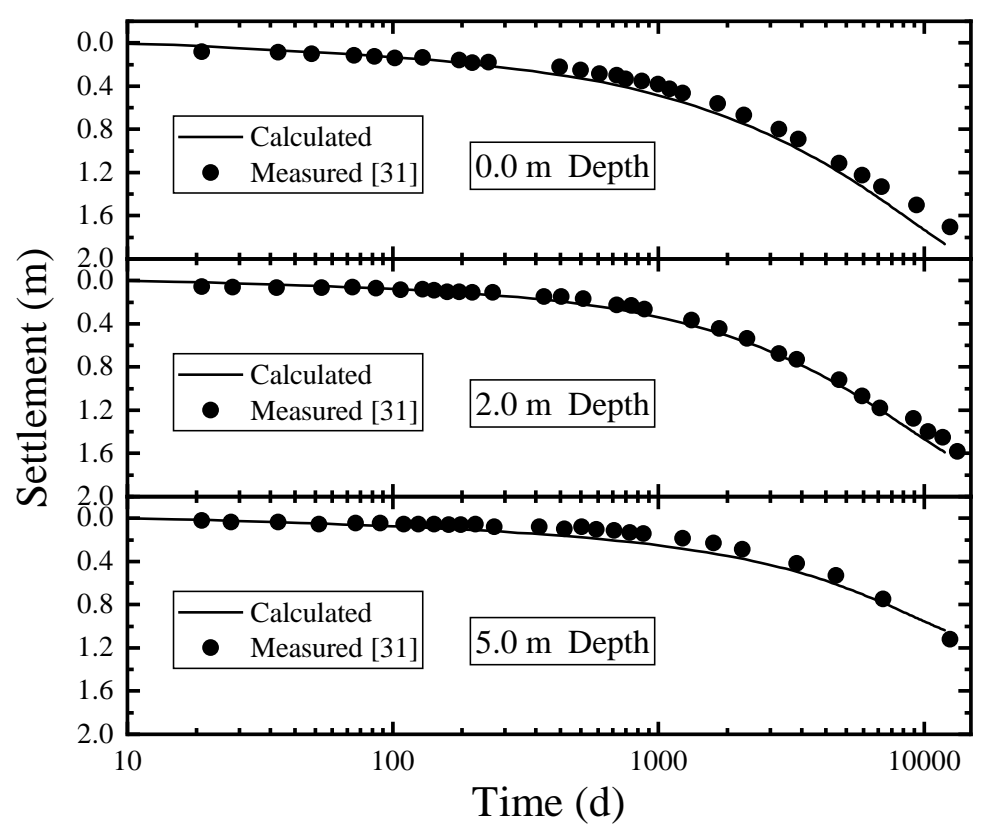

Figure 6. Comparisons of calculated and measured settlement along time.

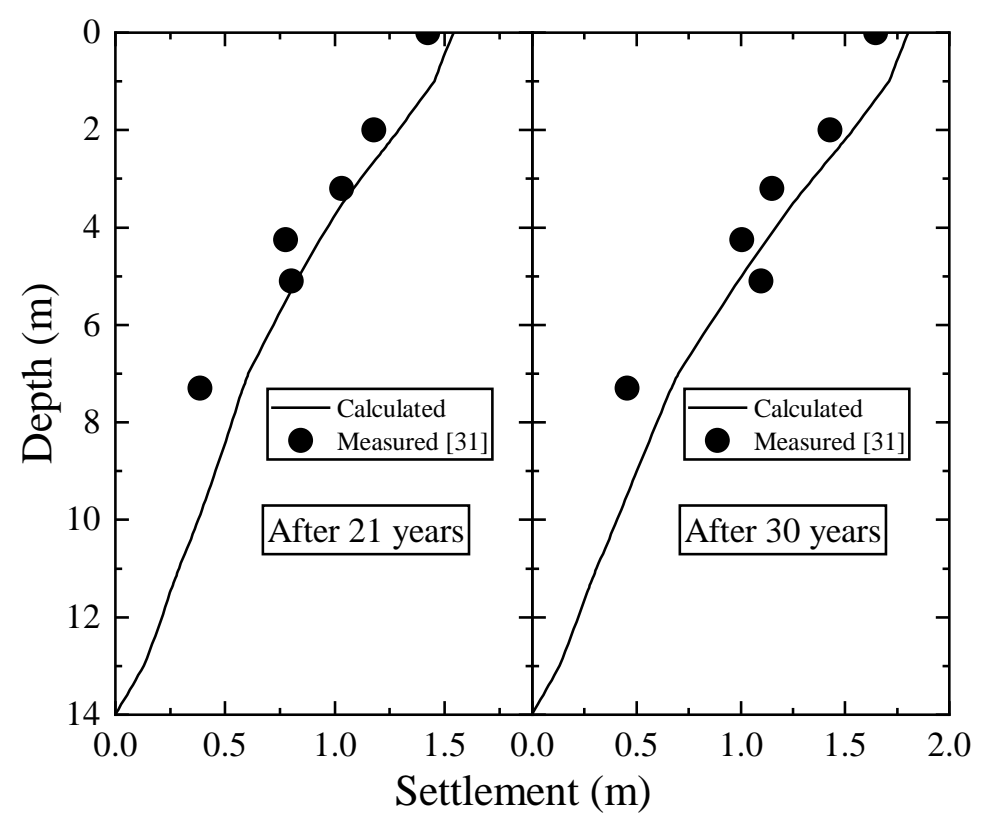

Figure 7. Comparisons of calculated and measured settlement along depth.

In the research of Mesri and Choi [31], the detailed variation of the average degree of consolidation was not given. Only the value of $82 \%$ after 32 years was presented according to the real settlement, which is almost the same as the calculated average degree of consolidation in this study (Figure 8). 


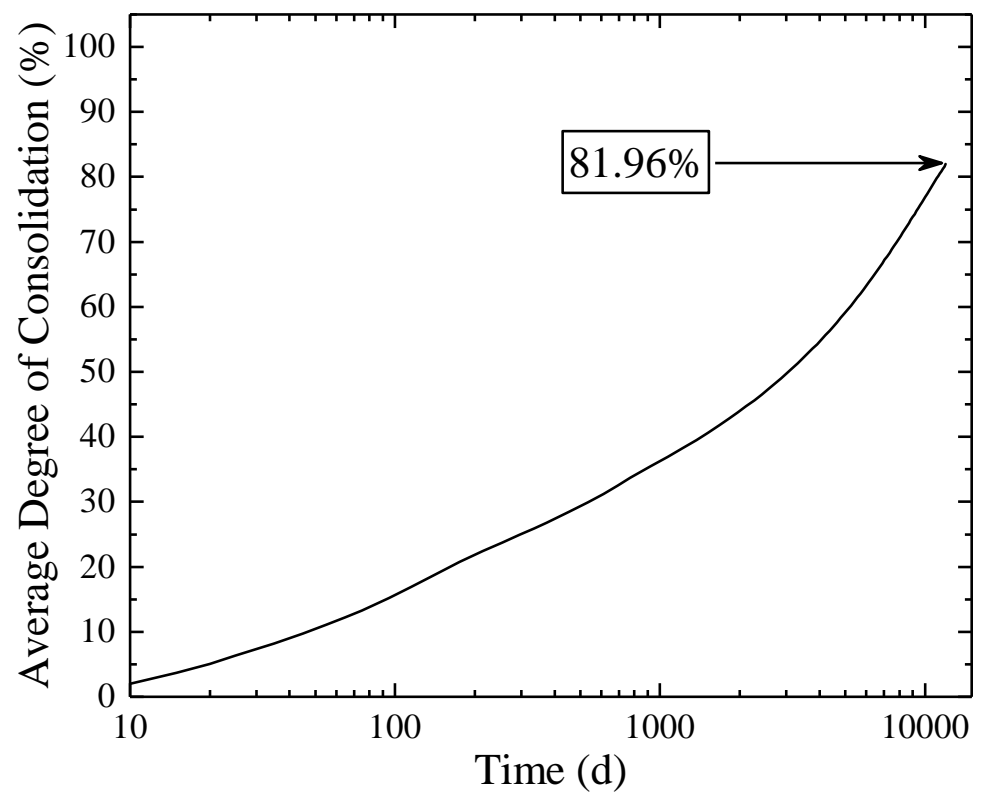

Figure 8. The variation of average degree of consolidation along time.

\section{Influence of Consolidation Status}

Three comparative cases are conducted here to show the importance of the separation of overconsolidation and normal consolidation: (1) Class A: complete overconsolidation, the initial preconsolidation pressure is $100 \mathrm{kPa}$; (2) Class $\mathrm{B}$ : overconsolidation and normal consolidation, the initial preconsolidation pressure is $50 \mathrm{kPa}$; (3) Class $\mathrm{C}$ : complete normal consolidation, the initial preconsolidation pressure is $10 \mathrm{kPa}$.

Figure 9 is the calculation diagram for all three cases, and the soil is vertically divided into 100 line elements. Assuming that the soil is homogeneous, and top and bottom surfaces are permeable, the total calculation time length is 1200 days. Table 2 lists the other parameters. The load is mathematically described in Equation (16), and the coefficient of consolidation is calculated using Equation (17).

$$
\begin{gathered}
q(t)= \begin{cases}70 t / 60 k P a & t \leq 60 \text { days } \\
70 k P a & t>60 \text { days }\end{cases} \\
C_{v}=\frac{k\left(1+e_{0}\right)}{\gamma_{w} a_{v}}
\end{gathered}
$$

where $C_{v}$ is the coefficient of consolidation.

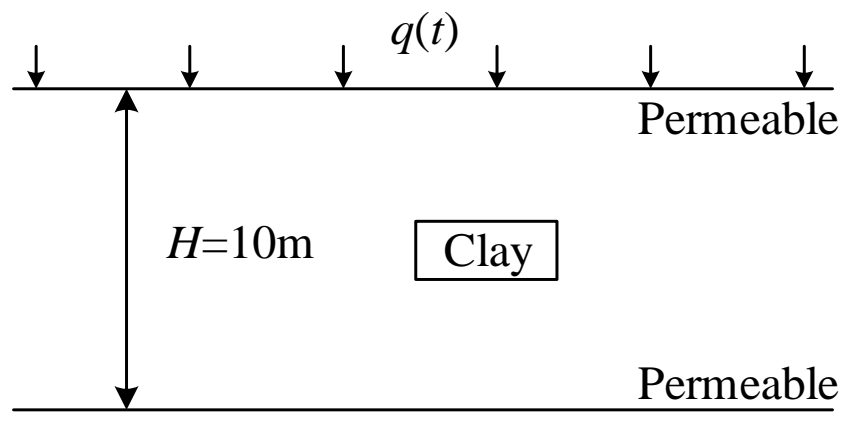

Figure 9. The calculation diagram for all three cases. 
Table 2. Calculation parameters.

\begin{tabular}{cccccccc}
\hline$k_{0}(\mathrm{~m} / \mathrm{d})$ & $C_{k}$ & $e_{0}$ & $C_{s}$ & $C_{c}$ & $\sigma_{0^{\prime}}(\mathbf{k P a})$ & $H(\mathrm{~m})$ & $\gamma_{w}\left(\mathbf{k N} / \mathrm{m}^{3}\right)$ \\
\hline 0.00008 & 1.5 & 0.8 & 0.1 & 0.5 & 10 & 10 & 10 \\
\hline
\end{tabular}

Figure 10 shows the variations of consolidation coefficients evaluated using Equation (17), during calculations at 2.5-2.6 m depth. As can be seen, the coefficients of consolidation remain stable for a period when the excess pore water pressure dissipates slowly under external loadings, (Figure 11) and hence, the effective stress maintains the same level. Subsequently, the coefficients of consolidation of Classes A and B increase nonlinearly as a result of the growth of the effective stress in soil, while that of Class $C$ still remains stable due to the slow dissipation of the excess pore water pressure. Therefore, the transition from overconsolidation to normal consolidation significantly affects the development of the coefficient of consolidation.

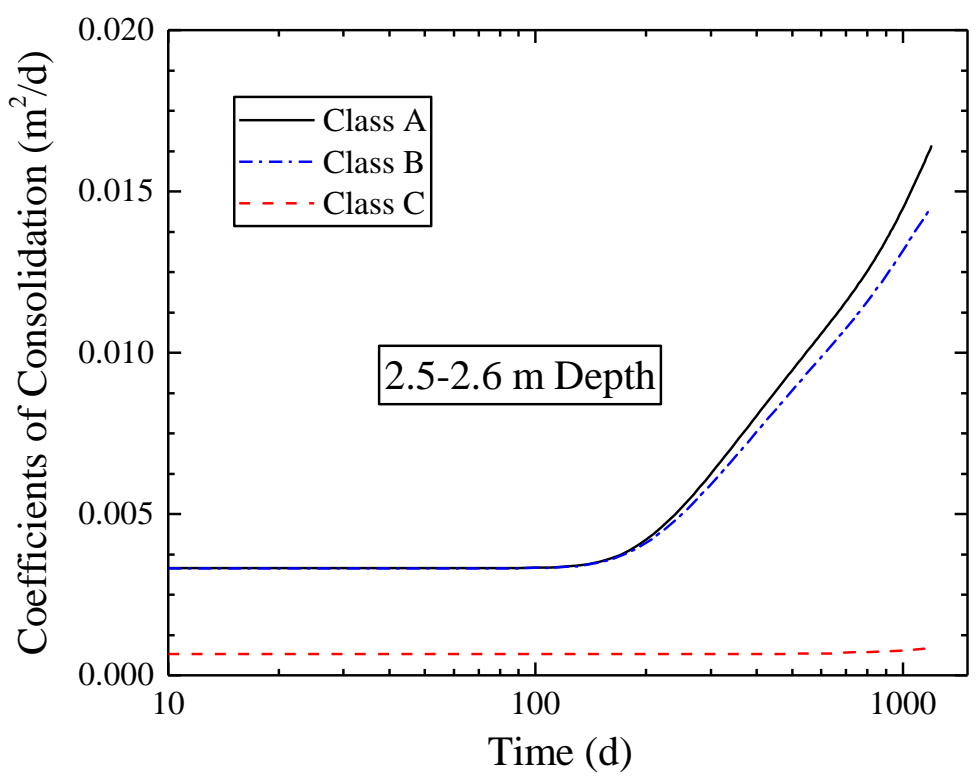

Figure 10. Comparisons of coefficients of consolidation at 2.5-2.6 m depth.

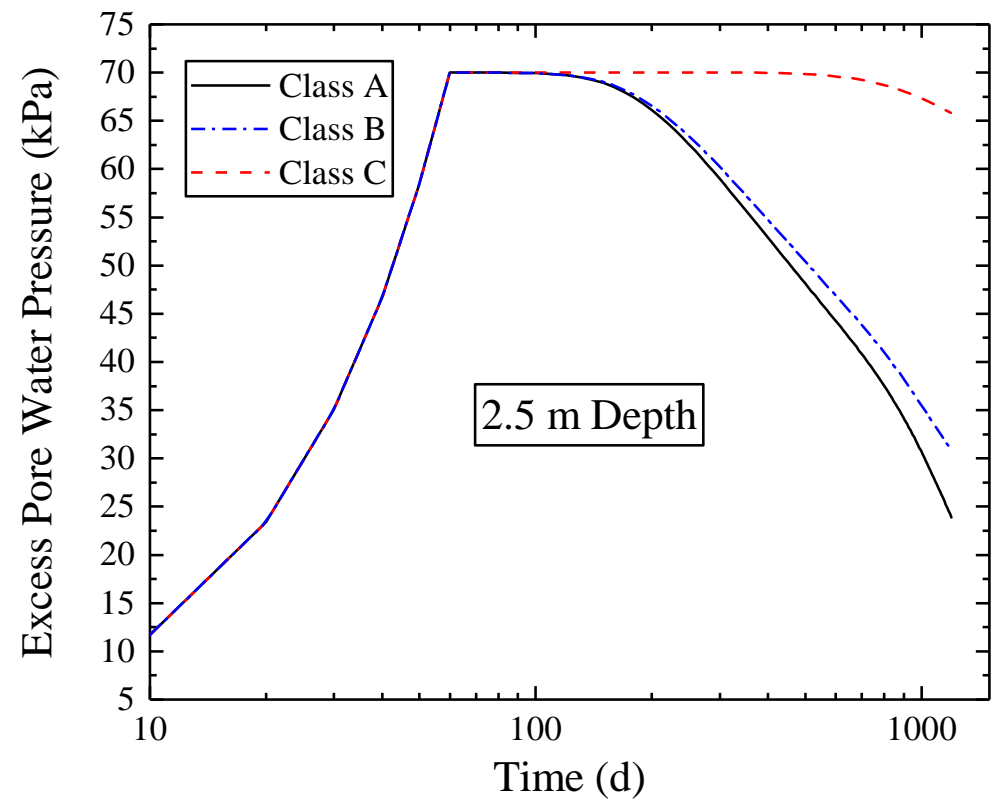

Figure 11. Comparisons of excess pore water pressure at $2.5 \mathrm{~m}$ depth. 
The excess pore water pressure of Class A at $2.5 \mathrm{~m}$ depth under normal consolidation is apparently larger than that under overconsolidation with the same external loadings (Figure 11). It follows that the compressibility under normal consolidation is larger according to Equation (4). As a result, the settlement under normal consolidation increases faster, being in accordance with the results shown in Figure 12. The results are in agreement and reveal that the separation of overconsolidation and normal consolidation during calculations has a significant influence on the accuracy of results.

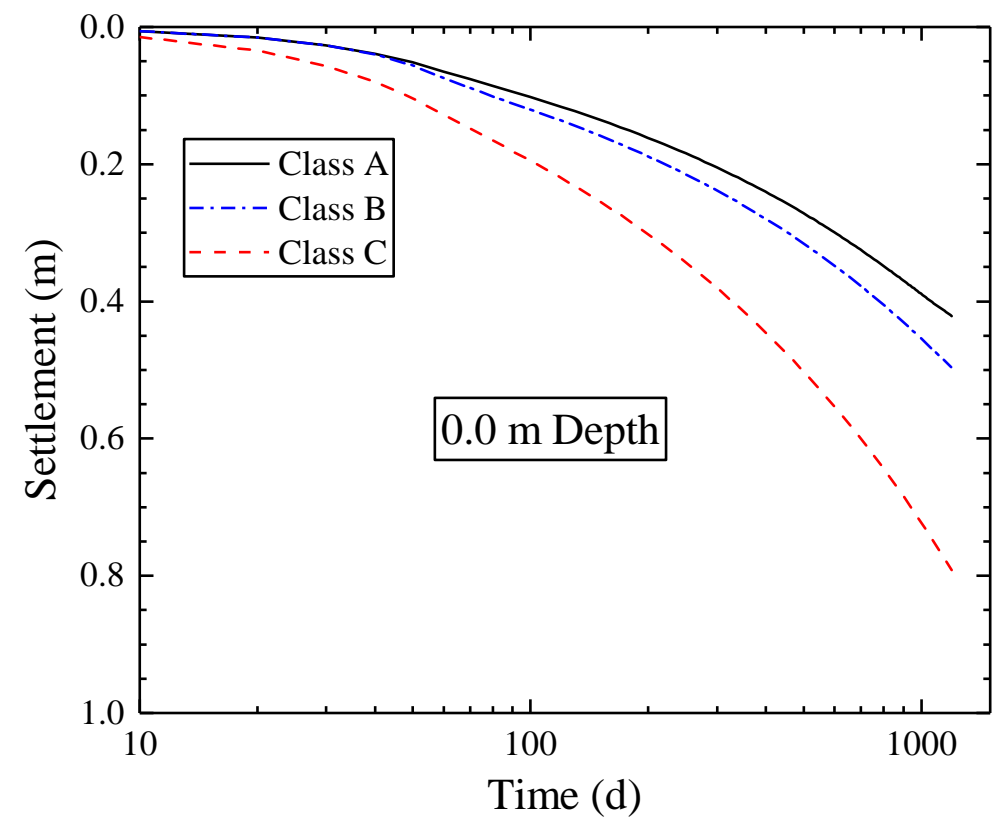

Figure 12. Comparisons of settlement at the top surface.

Figure 13 illustrates the evolutions of the average degree of consolidation, which is an important indicator for assessing the development of consolidation. The curves reveal that the average degree of consolidation is significantly influenced by different consolidation statuses, and the trends are consistent with those in Figure 11. In addition, the consolidation rate under normal consolidation is slower than that under overconsolidation.

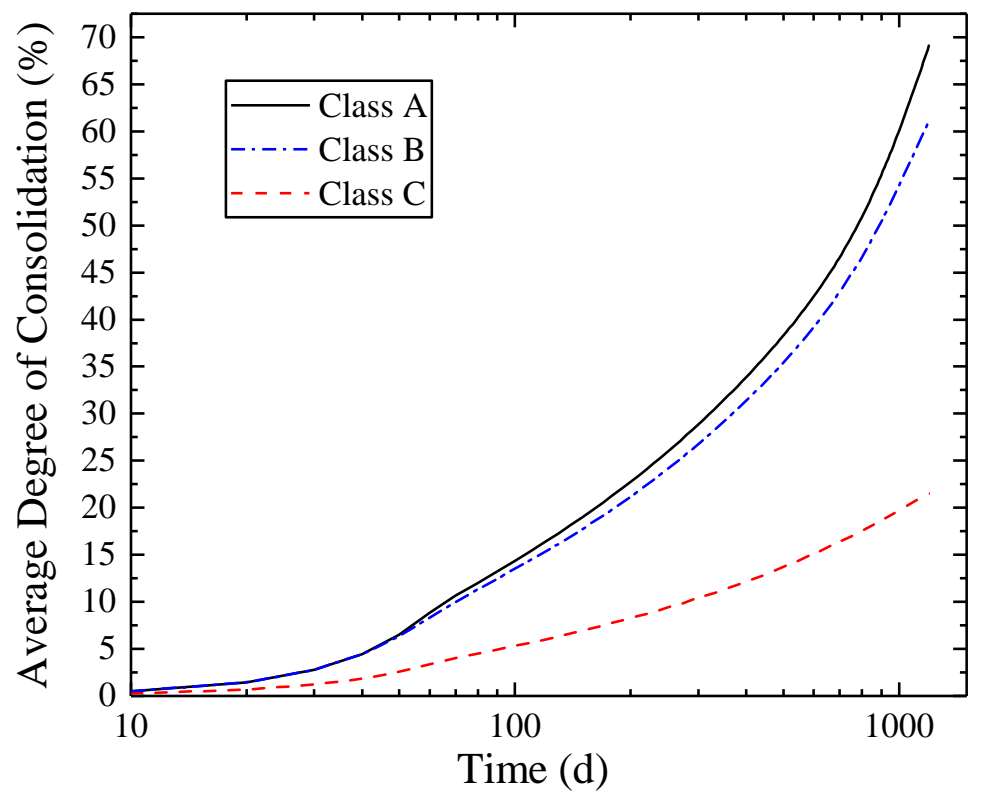

Figure 13. Comparisons of average degree of consolidation. 
To investigate the errors between the results obtained using nonlinear and constant coefficients, three control cases, using constant compressibility and permeability, were conducted. Table 3 lists the errors of settlement and the excess pore water pressure (EPWP) evaluated at $2.5 \mathrm{~m}$ depth at typical time points. The results show the nonignorable influence of nonlinearity of coefficients, and the errors are larger at longer elapsed times. Furthermore, the errors under normal consolidation are lower than those under overconsolidation.

Table 3. Errors between results obtained using nonlinear and constant coefficients at $2.5 \mathrm{~m}$ depth.

\begin{tabular}{ccccccc}
\hline \multirow{2}{*}{ Time (Day) } & \multicolumn{2}{c}{ Class A } & \multicolumn{2}{c}{ Class B } & \multicolumn{2}{c}{ Class C } \\
\cline { 2 - 7 } & Settlement (\%) & EPWP (\%) & Settlement (\%) & EPWP (\%) & Settlement (\%) & EPWP (\%) \\
\hline 200 & 24.30 & 4.61 & 26.67 & 4.02 & 7 & 0 \\
400 & 28.68 & 16.17 & 29.91 & 14.22 & 7.06 & 0.02 \\
600 & 29.62 & 21.94 & 30.67 & 19.31 & 7.25 & 0.24 \\
800 & 30.02 & 27.10 & 30.99 & 23.36 & 7.58 & 0.71 \\
1000 & 30.25 & 35.01 & 31.27 & 28.45 & 7.98 & 1.34 \\
1200 & 30.10 & 45.59 & 31.32 & 33.44 & 8.37 & 2.02 \\
\hline
\end{tabular}

\section{Conclusions}

In this paper, the compression index and the recompression index are used for evaluating solution-dependent nonlinear compressibility, and the $e$-log $k$ relation is used to calculate nonlinear permeability. The complex nonlinear consolidation is described using these two nonlinear coefficients. Moreover, the finite element method is adopted to solve the nonlinear consolidation equation suitable for small deformation problems with consideration of the time-dependent load. The main findings are summarized below:

(1) The coefficient of consolidation varies nonlinearly during the development of consolidation, due to the change of the effective stress in soil. In particular, the transition from overconsolidation to normal consolidation will exert a significant influence on the coefficient of consolidation;

(2) The two statuses of overconsolidation and normal consolidation should be separately dealt with in consolidation calculations, and using only one kind of consolidation status in calculations fails to accurately reflect real cases;

(3) The nonlinear variations of coefficients in soil exhibit a slighter influence on results under normal consolidation compared with the influence on results under overconsolidation;

(4) The solution presented in this paper is verified through a published engineering case. It is proved that the method is effective, stable, and accurate for meeting engineering requirements.

Author Contributions: Methodology, C.X.; software, C.X.; validation, C.X.; investigation, C.X.; writing-original draft preparation, C.X.; writing-review and editing, S.P.; funding acquisition, S.P. All authors have read and agreed to the published version of the manuscript.

Funding: This research was funded by a research grant (Project No. 51,909,233) from the National Natural Science Foundation of China (NSFC).

Acknowledgments: Special thanks to Chao Su and Jianqun Jiang for providing instructions and suggestions on this work.

Conflicts of Interest: The authors declare no conflict of interest.

\section{References}

1. Terzaghi, K.; Peck, R.B.; Mesri, G. Soil Mechanics in Engineering Practice, 3rd ed.; John Wiley \& Sons: Hoboken, NJ, USA, 1996.

2. Huang, J.; Griffiths, D.V. One-Dimensional Consolidation Theories for Layered Soil and Coupled and Uncoupled Solutions by the Finite-Element Method. Géotechnique 2010, 60, 709-713. [CrossRef]

3. Davis, E.H.; Raymond, G.P. A Non-Linear Theory of Consolidation. Géotechnique 1965, 15, 161-173. [CrossRef] 
4. Abbasi, N.; Rahimi, H.; Javadi, A.A.; Fakher, A. Finite Difference Approach for Consolidation with Variable Compressibility and Permeability. Comput. Geotech. 2007, 34, 41-52. [CrossRef]

5. Yazdani, H.; Toufigh, M.M. Nonlinear Consolidation of Soft Clays Subjected to Cyclic Loading-Part I: Theory. Geomech. Eng. 2012, 4, 229-241. [CrossRef]

6. Rujikiatkamjorn, C.; Indraratna, B. Analytical Solution for Radial Consolidation Considering Soil Structure Characteristics. Can. Geotech. J. 2014, 52, 947-960. [CrossRef]

7. Abuel-Naga, H.M.; Bergado, D.T.; Gniel, J. Design Chart for Prefabricated Vertical Drains Improved Ground. Geotext. Geomembr. 2015, 43, 537-546. [CrossRef]

8. Buddhima, I.; Rui, Z.; Fox, P.J.; Cholachat, R. Large-Strain Vacuum-Assisted Consolidation with Non-Darcian Radial Flow Incorporating Varying Permeability and Compressibility. J. Geotech. Geoenvironmental Eng. 2017, 143, 04016088.

9. Hui, W.; Liming, H.; Wengang, Q.; Qingbo, W. Analytical Solution for Electroosmotic Consolidation Considering Nonlinear Variation of Soil Parameters. Int. J. Geomech. 2017, 17, 06016032.

10. Feng, W.-Q.; Yin, J.-H. Development and Verification of a New Simplified Method for Calculating Settlement of a Thick Soil Layer with Nonlinear Compressibility and Creep. Int. J. Geomech. 2020, 20, 04019184. [CrossRef]

11. Conte, E.; Troncone, A. One-Dimensional Consolidation under General Time-Dependent Loading. Can. Geotech. J. 2006, 43, 1107-1116. [CrossRef]

12. Hsu, T.-W.; Liu, H.-J. Consolidation for Radial Drainage under Time-Dependent Loading. J. Geotech. Geoenvironmental Eng. 2013, 139, 2096-2103. [CrossRef]

13. Lu, M.; Wang, S.; Sloan, S.W.; Indraratna, B.; Xie, K. Nonlinear Radial Consolidation of Vertical Drains under a General Time-Variable Loading. Int. J. Numer. Anal. Methods Geomech. 2015, 39, 51-62. [CrossRef]

14. Hsu, T.-W.; Tsai, T.-H. Combined Vertical and Radial Consolidation under Time-Dependent Loading. Int. J. Geomech. 2016, 16, 04015073. [CrossRef]

15. Huang, M.; Li, J. Consolidation of Viscoelastic Soil by Vertical Drains Incorporating Fractional-Derivative Model and Time-Dependent Loading. Int. J. Numer. Anal. Methods Geomech. 2019, 43, 239-256. [CrossRef]

16. Xie, K.-H.; Xie, X.-Y.; Jiang, W. A Study on One-Dimensional Nonlinear Consolidation of Double-Layered Soil. Comput. Geotech. 2002, 29, 151-168. [CrossRef]

17. Tang, X.; Niu, B.; Cheng, G.; Shen, H. Closed-Form Solution for Consolidation of Three-Layer Soil with a Vertical Drain System. Geotext. Geomembr. 2013, 36, 81-91. [CrossRef]

18. Liu, J.-C.; Lei, G.-H.; Zheng, M.-X. General Solutions for Consolidation of Multilayered Soil with a Vertical Drain System. Geotext. Geomembr. 2014, 42, 267-276. [CrossRef]

19. Moradi, M.; Keshavarz, A.; Fazeli, A. One Dimensional Consolidation of Multi-Layered Unsaturated Soil under Partially Permeable Boundary Conditions and Time-Dependent Loading. Comput. Geotech. 2019, 107, 45-54. [CrossRef]

20. Zhao, X.-D.; Liu, Y.; Gong, W.-H. Analytical Solution for One-Dimensional Electro-Osmotic Consolidation of Double-Layered System. Comput. Geotech. 2020, 122, 103496. [CrossRef]

21. Liu, J.-C.; Lei, G.H. One-Dimensional Consolidation of Layered Soils with Exponentially Time-Growing Drainage Boundaries. Comput. Geotech. 2013, 54, 202-209. [CrossRef]

22. Fu, C.; Lei, G. A General Solution for Vertical-Drain Consolidation with Impeded Drainage Boundaries. J. Cent. South Univ. 2016, 23, 934-943. [CrossRef]

23. Wang, L.; Sun, D.; Qin, A. Semi-Analytical Solution to One-Dimensional Consolidation for Unsaturated Soils with Exponentially Time-Growing Drainage Boundary Conditions. Int. J. Geomech. 2018, 18, 04017144. [CrossRef]

24. Feng, J.; Ni, P.; Mei, G. One-Dimensional Self-Weight Consolidation with Continuous Drainage Boundary Conditions: Solution and Application to Clay-Drain Reclamation. Int. J. Numer. Anal. Methods Geomech. 2019, 43, 1634-1652. [CrossRef]

25. Hansbo, S. Consolidation Equation Valid for both Darcian and Non-Darcian Flow. Géotechnique 2001, 51, 51-54. [CrossRef]

26. Li, C.; Xie, K. One-Dimensional Nonlinear Consolidation of Soft Clay with the Non-Darcian Flow. J. Zhejiang Univ. Sci. A 2013, 14, 435-446. [CrossRef]

27. Mishra, A.; Patra, N.R. Long-Term Response of Consolidating Soft Clays around a Pile Considering Non-Darcian Flow. Int. J. Geomech. 2019, 19, 04019040. [CrossRef] 
28. Liu, Z.; Zhang, J.; Duan, S.; Xia, Y.; Cui, P. A Consolidation Modelling Algorithm Based on the Unified Hardening Constitutive Relation and Hansbo's Flow Rule. Comput. Geotech. 2020, 117, 103233. [CrossRef]

29. Sandhu, R.S.; Liu, H.; Singh, K.J. Numerical Performance of Some Finite Element Schemes for Analysis of Seepage in Porous Elastic Media. Int. J. Numer. Anal. Methods Geomech. 1977, 1, 177-194. [CrossRef]

30. Smith, I.M.; Griffiths, D.V.; Margetts, L. Programming the Finite Element Method, 5th ed.; John Wiley \& Sons: Hoboken, NJ, USA, 2013.

31. Mesri, G.; Choi, Y.K. Settlement Analysis of Embankments on Soft Clays. J. Geotech. Eng. 1985, 111, 441-464. [CrossRef]

32. Buddhima, I.; Sudip, B.; Cholachat, R. Numerical Solution of Stone Column-Improved Soft Soil Considering Arching, Clogging, and Smear Effects. J. Geotech. Geoenvironmental Eng. 2013, 139, 377-394.

33. Ma, B.-H.; Hu, Z.-Y.; Li, Z.; Cai, K.; Zhao, M.-H.; He, C.-B.; Huang, X.-C. Finite Difference Method for the One-Dimensional Non-Linear Consolidation of Soft Ground under Uniform Load. Front. Earth Sci. 2020, 8, 1-9. [CrossRef]

34. Chen, R.P.; Zhou, W.H.; Wang, H.Z.; Chen, Y.M. One-Dimensional Nonlinear Consolidation of Multi-Layered Soil by Differential Quadrature Method. Comput. Geotech. 2005, 32, 358-369. [CrossRef]

35. Rohan, W.; Buddhima, I.; Nagaratnam, S. Vertical and Radial Consolidation Analysis of Multilayered Soil Using the Spectral Method. J. Geotech. Geoenvironmental Eng. 2009, 135, 657-663.

36. Yang, C.; Carter, J.P. 1-D Finite Strain Consolidation Analysis Based on Isotach Plasticity: Class A and Class C Predictions of the Ballina Embankment. Comput. Geotech. 2018, 93, 42-60. [CrossRef]

37. Lim, G.T.; Pineda, J.A.; Boukpeti, N.; Carraro, J.A.H. Predicted and Measured Behaviour of an Embankment on PVD-Improved Ballina Clay. Comput. Geotech. 2018, 93, 204-221. [CrossRef]

38. Das, B.M. Advanced Soil Mechanics, 4th ed.; CRC Press: London, UK, 2013.

(C) 2020 by the authors. Licensee MDPI, Basel, Switzerland. This article is an open access article distributed under the terms and conditions of the Creative Commons Attribution (CC BY) license (http://creativecommons.org/licenses/by/4.0/). 